\title{
Maintenance Management and Modeling in Modern Manufacturing Systems
}

Mehmet Savsar

\section{Introduction}

The cost of maintenance in industrial facilities has been estimated as $15-40 \%$ (an average of 28\%) of total production costs (Mobley, 1990; Sheu and Krajewski, 1994). The amount of money that companies spent yearly on maintenance can be as large as the net income earned (McKone and Wiess, 1998). Modern manufacturing systems generally consist of automated and flexible machines, which operate at much higher rates than the traditional or conventional machines. While the traditional machining systems operate at as low as 20\% utilization rates, automated and Flexible Manufacturing Systems (FMS) can operate at 70-80\% utilization rates (Vineyard and Meredith, 1992). As a result of this higher utilization rates, automated manufacturing systems may incur four times more wear and tear than traditional manufacturing systems. The effect of such an accelerated usage on system performance is not well studied. However, the accelerated usage of an automated system would result in higher failure rates, which in turn would increase the importance of main$\varepsilon$ tenance and maintenance-related activities as well as effective maintenance $\stackrel{0}{\circ}$ management. While maintenance actions can reduce the effects of breakdowns 扂 due to wear-outs, random failures are still unavoidable. Therefore, it is important to understand the implications of a given maintenance plan on a system before the implementation of such a plan.

Modern manufacturing systems are built according to the volume/variety ratio $\Phi$ of production. A facility may be constructed either for high variety of prod$\frac{\pi}{\pi}$ ucts, each with low volume of production, or for a special product with high 踏 volume of production. In the first case, flexible machines are utilized in a job \& shop environment to produce a variety of products, while in the second case ¿ special purpose machinery are serially linked to form transfer lines for high

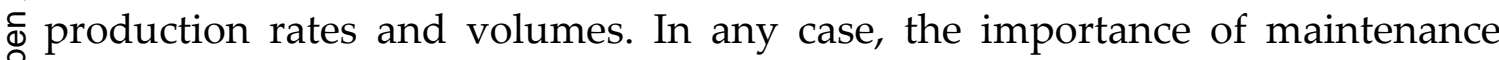
function has increased due to its role in keeping and improving the equipment 
availability, product quality, safety requirements, and plant cost-effectiveness levels since maintenance costs constitute an important part of the operating budget of manufacturing firms (Al-Najjar and Alsyouf, 2003).

Without a rigorous understanding of their maintenance requirements, many machines are either under-maintained due to reliance on reactive procedures in case of breakdown, or over-maintained by keeping the machines off line more than necessary for preventive measures. Furthermore, since industrial systems evolve rapidly, the maintenance concepts will also have to be reviewed periodically in order to take into account the changes in systems and the environment. This calls for implementation of flexible maintenance methods with feedback and improvement (Waeyenbergh and Pintelon, 2004).

Maintenance activities have been organized under different classifications. In the broadest way, three classes are specified as (Creehan, 2005):

1. Reactive: Maintenance activities are performed when the machine or a function of the machine becomes inoperable. Reactive maintenance is also referred to as corrective maintenance (CM).

2. Preventive: Maintenance activities are performed in advance of machine failures according to a predetermined time schedule. This is referred to as preventive maintenance (PM).

3. Predictive/Condition-Based: Maintenance activities are performed in advance of machine failure when instructed by an established condition monitoring and diagnostic system.

Several other classifications, as well as different names for the same classifications, have been stated in the literature. While CM is an essential repair activity as a result of equipment failure, the voluntary PM activity was a concept adapted in Japan in 1951. It was later extended by Nippon Denso Co. in 1971 to a new program called Total Productive Maintenance (TPM), which assures effective PM implementation by total employee participation. TPM includes Maintenance Prevention (MP) and Maintainability Improvement (MI), as well as PM. This also refers to "maintenance-free" design through the incorporation of reliability, maintainability, and supportability characteristics into the equipment design. Total employee participation includes Autonomous Maintenance (AM) by operators through group activities and team efforts, with operators being held responsible for the ultimate care of their equipments (Chan et al., 2005). 
The existing body of theory on system reliability and maintenance is scattered over a large number of scholarly journals belonging to a diverse variety of disciplines. In particular, mathematical sophistication of preventive maintenance models has increased in parallel to the growth in the complexity of modern manufacturing systems. Extensive research has been published in the areas of maintenance modeling, optimization, and management. Excellent reviews of maintenance and related optimization models can be seen in (Valdez-Flores and Feldman, 1989; Cho and Parlar, 1991; Pintelon and Gelders, 1992; and Dekker, 1996).

Limited research studies have been carried out on the maintenance related issues of FMS (Kennedy, 1987; Gupta et al., 1988; Lin et al., 1994; Sun, 1994). Related analysis include effects of downtimes on uptimes of CNC machines, effects of various maintenance policies on FMS failures, condition monitoring system to increase FMS and stand-alone flexible machine availabilities, automatic data collection, statistical data analysis, advanced user interface, expert system in maintenance planning, and closed queuing network models to optimize the number of standby machines and the repair capacity for FMS. Recent studies related to FMS maintenance include, stochastic models for FMS availability and productivity under CM operations (Savsar, 1997a; Savsar, 2000) and under PM operations (Savsar, 2005a; Savsar, 2006).

In case of serial production flow lines, literature abounds with models and techniques for analyzing production lines under various failure and maintenance activities. These models range from relatively straight-forward to extremely complex, depending on the conditions prevailing and the assumptions made. Particularly over the past three decades a large amount of research has been devoted to the analysis and modeling of production flow line systems under equipment failures (Savsar and Biles, 1984; Boukas and Hourie, 1990; Papadopoulos and Heavey, 1996; Vatn et al., 1996; Ben-Daya and Makhdoum, 1998; Vouros et al., 2000; Levitin and Meizin, 2001; Savsar and Youssef, 2004; Castro and Cavalca, 2006; Kyriakidis and Dimitrakos, 2006). These models consider the production equipment as part of a serial system with various other operational conditions such as random part flows, operation times, intermediate buffers with limited capacity, and different types of maintenance activities on each equipment. Modeling of equipment failures with more than one type of maintenance on a serial production flow line with limited buffers is relatively complicated and need special attention. A comprehensive model and an iterative computational procedure has been developed (Savsar, 2005b) 
to study the effects of different types of maintenance activities and policies on productivity of serial lines under different operational conditions, such as finite buffer capacities and equipment failures. Effects of maintenance policies on system performance when applied during an opportunity are discussed by (Dekker and Smeitnik, 1994). Maintenance policy models for just-in-time production control systems are discussed by (Albino, et al., 1992 and Savsar, 1997b).

In this chapter, procedures that combine analytical and simulation models to analyze the effects of corrective, preventive, opportunistic, and other maintenance policies on the performance of modern manufacturing systems are presented. In particular, models and results are provided for the FMS and automated Transfer Lines. Such performance measures as system availability, production rate, and equipment utilization are evaluated as functions of different failure/repair conditions and various maintenance policies.

\section{Maintenance Modeling in Modern Manufacturing Systems}

It is known that the probability of failure increases as an equipment is aged, and that failure rates decrease as a result of PM and TPM implementation. However, the amount of reduction in failure rate, from the introduction of PM activities, has not been studied well. In particular, it is desirable to know the performance of a manufacturing system before and after the introduction of PM. It is also desirable to know the type and the rate at which preventive maintenance should be scheduled. Most of the previous studies, which deal with maintenance modeling and optimization, have concentrated on finding an optimum balance between the costs and benefits of preventive maintenance. The implementation of PM could be at scheduled times (scheduled PM) or at other times, which arise when the equipment is stopped because of other reasons (opportunistic PM). Corrective maintenance (CM) policy is adapted if equipment is to be maintained only when it fails. The best policy has to be selected for a given system with respect to its failure, repair, and maintenance characteristics.

Two well-known preventive maintenance models originating from the past research are called age-based and block-based replacement models. In both models, PM is scheduled to be carried out on the equipment. The difference is in the timing of consecutive PM activities. In the aged-based model, if a failure occurs before the scheduled PM, PM is rescheduled from the time the corrective 
maintenance is completed on the equipment. In the block-based model, on the other hand, PM is always carried out at scheduled times regardless of the time of equipment failures and the time that corrective maintenance is carried out. Several other maintenance models, based on the above two concepts, have been discussed in the literature as listed above.

One of the main concerns in PM scheduling is the determination of its effects on time between failures (TBF). Thus, the basic question is to figure out the amount of increase in TBF due to implementation of a PM. As mentioned above, introduction of PM reduces failure rates by eliminating the failures due to wear outs. It turns out that in some cases, we can theoretically determine the amount of reduction in total failure rate achieved by separating failures due to wear outs from the failures due to random causes.

\subsection{Mathematical Modeling for Failure Rates Partitioning}

Following is a mathematical procedure to separate random failures from wearout failures. This separation is needed in order to be able to see the effects of maintenance on the productivity and operational availability of an equipment or a system. The procedure outlined here can be utilized in modeling and simulating maintenance operations in a system.

Let $f(t)=$ Probability distribution function (pdf) of time between failures.

$F(t)=$ Cumulative distribution function $(\mathrm{cdf})$ of time between failures.

$R(t)=$ Reliability function (probability of equipment survival by time $t$ ).

$h(t)=$ Hazard rate (or instantaneous failure rate of the equipment).

Hazard rate $h(t)$ can be considered as consisting of two components, the first from random failures and the second from wear-out failures, as follows:

$$
h(t)=h_{1}(t)+h_{2}(t)
$$

Since failures are from both, chance causes (unavoidable) and wear-outs (avoidable), reliability of the equipment by time $t$, can be expressed as follows:

$$
R(t)=R 1(t) R 2(t)
$$

Where, $R_{1}(t)=$ Reliability due to chance causes or random failures and $R_{2}(t)=$ Reliability from wear-outs, $h_{1}(t)=$ Hazard rate from random failures, and $h_{2}(t)$ 
$=$ Hazard rate from wear-out failures. Since the hazard rate from random failures is independent of aging and therefore constant over time, we let $h_{1}(t)=\lambda$. Thus, the reliability of the equipment from random failures with constant hazard rate:

$$
\mathrm{R}_{1}(\mathrm{t})=\mathrm{e}^{-\lambda_{\mathrm{t}}} \text { and } \mathrm{h}(\mathrm{t})=\lambda+\mathrm{h}_{2}(\mathrm{t})
$$

It is known that:

$$
\begin{gathered}
\mathrm{h}(\mathrm{t})=\mathrm{f}(\mathrm{t}) / \mathrm{R}(\mathrm{t})=\mathrm{f}(\mathrm{t}) /[1-\mathrm{F}(\mathrm{t})]=\lambda+\mathrm{h}_{2}(\mathrm{t}) \\
\mathrm{h}_{2}(\mathrm{t})=\mathrm{h}(\mathrm{t})-\mathrm{h}_{1}(\mathrm{t})=\mathrm{f}(\mathrm{t}) /[1-\mathrm{F}(\mathrm{t})]-\lambda \\
\mathrm{R}_{2}(\mathrm{t})=\mathrm{R}(\mathrm{t}) / \mathrm{R}_{1}(\mathrm{t})=[1-\mathrm{F}(\mathrm{t})] / \mathrm{e}^{-\lambda_{\mathrm{t}}} \\
\mathrm{h}_{2}(\mathrm{t})=\mathrm{f}_{2}(\mathrm{t}) / \mathrm{R}_{2}(\mathrm{t}) \\
f_{2}(t)=h_{2}(t) R_{2}(t)=\left[\frac{f(t)}{1-F(t)}-\lambda\right]\left[\frac{1-F(t)}{e^{-\lambda t}}\right]=\frac{f(t)}{e^{-\lambda t}}-\frac{\lambda}{e^{-\lambda t}}[1-F(t)]
\end{gathered}
$$

where

$$
f_{2}(t)=\frac{d F_{2}(t)}{d t} \quad F_{2}(t)=1-R_{2}(t)=1-\frac{1-F(t)}{e^{-\lambda t}}=\frac{e^{-\lambda t}-R(t)}{e^{-\lambda t}}
$$

Equation (8) can be used to determine $f_{2}(t)$. These equations show that total time between failures, $f(t)$, can be separated into two distributions, time between failures from random causes, with pdf given by $f_{1}(t)$, and time between failures from wear-outs, with pdf given by $\mathrm{f}_{2}(\mathrm{t})$. Since the failures from random causes could not be eliminated, we concentrate on decreasing the failures from wear-outs by using appropriate maintenance policies. By the procedure described above, it is possible to separate the two types of failures and develop the best maintenance policy to eliminate wear-out failures. It turns out that this separation is analytically possible for uniform distribution. However, it is not possible for other distributions. Another approach is used for other distribu- 
tions when analyzing and implementing PM operations. Separation of failure rates is particularly important in simulation modeling and analysis of maintenance operations. Failures from random causes are assumed to follow an exponential distribution with constant hazard rate since they are unpredictable and do not depend on operation time of equipment. Exponential distribution is the type of distribution that has memoryless property; a property that results in constant failure rates over time regardless of aging and wear outs due to usage. Following section describes maintenance modeling for different types of distributions.

\subsection{Uniform Time to Failure Distribution}

For uniformly-distributed time between failures, $t$, in the interval $0<t<\mu$, the pdf of time between failures without introduction of PM is given by: $f(t)=1 / \mu$. If we let $\alpha=1 / \mu$, then $\mathrm{F}(\mathrm{t})=\alpha \mathrm{t}$ and reliability is given as $R(t)=1-\alpha \mathrm{t}$ and the total failure rate is given as $h(t)=f(t) / R(t)=\alpha /(1-\alpha t)$. If we assume that the hazard rate from random failures is a constant given by $h_{1}(t)=\alpha$, then the hazard rate from wear-out failures can be determined by $h_{2}(t)=h(t)-h_{1}(t)=\alpha /(1-\alpha t)$ $\alpha=\alpha^{2} t /(1-\alpha t)$. The corresponding time to failure pdf for each type of failure rate is as follows:

$$
\begin{array}{ll}
f_{1}(t)=\alpha \times e^{(-\alpha t)}, & 0<t<\mu \\
f_{2}(t)=\alpha^{2} \times t \times e^{(\alpha t)}, & 0<t<\mu
\end{array}
$$

The reliability function for each component is as follows:

$$
\begin{array}{cc}
R_{1}(t)=e^{(-\alpha t)}, & 0<t<\mu \\
R_{2}(t)=(1-\alpha t) \times e^{\alpha t}, & 0<t<\mu \\
R(t)=R_{1}(t) \times R_{2}(t)
\end{array}
$$


When PM is introduced, failures from wear-outs are eliminated and thus the machines fail only from random failures, which are exponentially distributed as given by $\mathrm{f}_{1}(\mathrm{t})$. Sampling for the time to failures in simulations is then based on an exponential distribution with mean $\mu$ and a constant failure rate of $\alpha=1 / \mu$. In case of $C M$ without PM, in addition to the random failures, wear-out failures are also present and thus the time between equipment failures is uniformly distributed between zero and $\mu$ as given by $\mathrm{f}(\mathrm{t})$. The justification behind this assumption is that uniform distribution implies an increasing failure rate with two components, namely, failure rate from random causes and failure rate from wear-out causes as given by $h_{1}(t)$ and $h_{2}(t)$, respectively. Initially when $t=0$, failures are from random causes with a constant rate $\alpha=1 / \mu$. As the equipment operates, wear-out failures occur and thus the total failure rate $h(t)$ increases with time $t$. Sampling for the time between failures in modeling and simulation is based on uniform distribution with mean $\mu / 2$ and increasing failure rate, $h(t)$.

\subsection{Non-uniform time to failure distributions}

\subsubsection{Normal distribution:}

If the times between failures are normally distributed, it is not possible to separate the two types of failures analytically. However, the following procedure can be implemented in simulation models:

When no preventive maintenance is implemented, times between failures are sampled from a normal distribution with mean $\mu$ and standard deviation $\sigma$. When PM is implemented, wear-out failures are eliminated and the remaining random failures follow an exponential distribution with constant failure rate with extended mean time between failures. It is assumed that mean time between equipment failures after introduction of PM extends from $\mu$ to $k \mu$, where $\mathrm{k}$ is a constant greater than 1 .

\subsubsection{Gamma Distribution:}

For a gamma distribution, which is Erlang when its shape parameter $\alpha$ is integer and exponential when $\alpha=1$, the expected value of random variable $T$ is defined by $E(T)=\alpha \beta$. Thus, by changing $\alpha$ and $\beta$ values, mean time between failures can be specified as required. When no PM is introduced, times between failures are sampled from a gamma distribution with mean time between fail- 
ures of $\alpha \beta$. If PM is introduced and wear-out failures are eliminated, times between failures are extended by a constant $k$. Therefore, sampling is made from an exponential distribution with mean $\mathrm{k}(\alpha \beta)$.

\subsubsection{Weibull Distribution:}

For the Weibull distribution, $\alpha$ is a shape parameter and $\beta$ is a scale parameter. The expected value of time between failures, $\mathrm{E}(\mathrm{T})=\mathrm{MTBF}=\beta \Gamma(1 / \alpha) / \alpha$, and its variance is $\mathrm{V}(\mathrm{T})=\beta^{2}\left[2 \Gamma(2 / \alpha)-\{\Gamma(1 / \alpha)\}^{2} / \alpha\right]$. For a given value of $\alpha$, $\beta=\alpha(\mathrm{MTBF}) / \Gamma(1 / \alpha)$. When there is no PM, times between failures are sampled from Weibull with parameters $\alpha$ and $\beta$ in simulation models. When PM is introduced, wear-out failures are eliminated and the random failures are sampled in simulation from an exponential distribution with mean $=\mathrm{k}[\beta \Gamma(1 / \alpha) / \alpha]$, where $\alpha$ and $\beta$ are the parameters of the Weibull distribution and $\mathrm{k}$ is a constant greater than 1 .

\subsubsection{Triangular Distribution:}

The triangular distribution is described by the parameters $a, m$, and $b$ (i.e., minimum, mode, and maximum). Its mean is given by $E(T)=(a+m+b) / 3$ and variance by $V(T)=\left(a^{2}+m^{2}+b^{2}-m a-a b-m b\right) / 18$. Since the times between failures can be any value starting from zero, we let $a=0$ and thus $m=b / 3$ from the property of a triangular distribution. Mean time between failures is $E(T)=(m+b) / 3=[b+b / 3] / 3=4 b / 9=4 m / 3$. If no $P M$ is introduced, time between failures are sampled in simulation from a triangular distribution with parameters $\mathrm{a}, \mathrm{m}, \mathrm{b}$ or $\mathrm{0}, \mathrm{b} / 3, \mathrm{~b}$. If PM is introduced, again wear-out failures are eliminated and the random failures are sampled from an exponential distribution with an extended mean of $\mathrm{k}[\mathrm{a}+\mathrm{m}+\mathrm{b}] / 3$, where $\mathrm{a}, \mathrm{m}$, and $\mathrm{b}$ are parameters of the triangular distribution that describe the time between failures. The multiplier $\mathrm{k}$ is a constant greater than 1.

\section{Analysis of the Effects of Maintenance Policies on FMS Availability}

Equipment in FMS systems can be subject to corrective maintenance; corrective maintenance combined with a preventive maintenance; and preventive maintenance implemented at different opportunities. FMS operates with an increasing failure rate due to random causes and wear-outs. The stream of mixed failures during system operation is separated into two types: (i) random failures due to chance causes; (ii) time dependent failures due to equipment usage 
and wear-outs. The effects of preventive maintenance policies (scheduled and opportunistic), which are introduced to eliminate wear-out failures of an FMS, can be investigated by analytical and simulation models. In particular, effects of various maintenance policies on system performance can be investigated under various time between failure distributions, including uniform, normal, gamma, triangular, and Weibull failure time distributions, as well as different repair and maintenance parameters.

\subsection{Types of Maintenance Policies}

In this section, five types maintenance policies, which resulted in six distinct cases, and their effects on FMS availability are described.

\section{i) No Maintenance Policy:}

In this case, a fully reliable FMS with no failures and no maintenance is considered.

\section{ii) Corrective Maintenance Policy (CM):}

The FMS receives corrective maintenance only when equipment fails. Time between equipment failures can follow a certain type of distribution. In case of uniform distribution, two different types of failures can be separated in modeling and analysis.

iii) Block-Based PM with CM Policy (BB):

In this case, the equipment is subject to preventive maintenance at the end of each shift to eliminate the wear out failures during the shift. However, regardless of any CM operations between the two scheduled PMs, the PM operations are always carried out as scheduled at the end of the shifts without affecting the production schedule. This policy is evaluated under various time between failure distributions. Figure 1 illustrates this maintenance process.

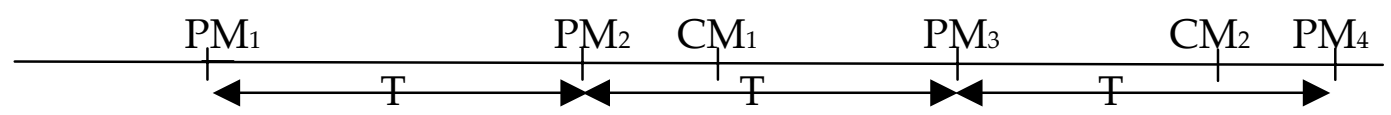

Figure 1. Illustration of PM operations under a block-based policy 
iv) Age-Based PM with CM Policy (AB):

In this policy, preventive maintenance is scheduled at the end of a shift, but the PM time changes as the equipment undergoes corrective maintenance. Suppose that the time between PM operations is fixed as T hours and before performing a particular PM operation the equipment fails. Then the CM operation is carried out and the next PM is rescheduled T hours from the time the repair for the $C M$ is completed. $C M$ has eliminated the need for the next PM. If the scheduled PM arrives before a failure occurs, PM is carried out as scheduled. Figure 2 illustrates this process.

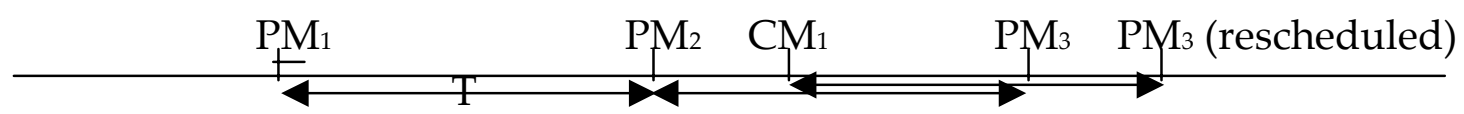

Figure 2. Illustration of PM operations under age-based policy.

v) Opportunity-Triggered PM with CM Policy (OT):

In this policy, $\mathrm{PM}$ operations are carried out only when they are triggered by failure. In other words, if a failure that requires CM occurs, it also triggers PM. Thus, corrective maintenance as well as preventive maintenance is applied to the machine together at the time of a failure. This is called triggered preventive maintenance. Since the equipment is already stopped and some parts are already maintained for the $C M$, it is expected that the PM time would be reduced in this policy. We assign a certain percentage of reduction in the PM operation. A 50\% reduction was assumed reasonable in the analysis below.

vi) Conditional Opportunity-Triggered PM with CM Policy (CO): In this policy, PM is performed on each machine at either scheduled times or when a specified opportunistic condition based on the occurrence of a CM arises. The maintenance management can define the specified condition. In our study, a specific condition is defined as follows: if a machine fails within the last quarter of a shift, before the time of next PM, the next PM will be combined with CM for this machine. In this case, PM scheduled at the end of the shift would be skipped. On the other hand, if a machine failure occurs before the last quarter of the shift, only CM is introduced and the PM is performed at the end of the shift as it was scheduled. This means that the scheduled PM is performed only for those machines that did not fail during the last quarter of the shift. 
The maintenance policies described above are compared under similar operating conditions by using simulation models with analytical formulas incorporated into the model as described in section 2. The FMS production rate is first determined under each policy. Then, using the production rate of a fully reliable FMS as a basis, an index, called Operational Availability Index ( $\left.\mathrm{OAI}_{\mathrm{i}}\right)$ of the FMS under each policy $\mathrm{i}$, is developed: $\mathrm{OAI}_{\mathrm{i}}=\mathrm{P}_{\mathrm{i}} / \mathrm{P}_{1}$, where $\mathrm{P}_{1}=$ production rate of the reliable FMS and $P_{i}=$ production rate of the FMS operated under maintenance policy $\mathrm{i}(\mathrm{i}=2,3,4,5$, and 6$)$. General formulation is described in section 2 for five different times between failure distributions and their implementation with respect to the maintenance policies. The following section presents a maintenance simulation case example for an FMS system.

\subsection{Simulation Modeling of FMS Maintenance Operations}

In order to analyze the performance measures of FMS operations under different maintenance policies, simulation models are developed for the fully reliable FMS and for each of the five maintenance related policies described above. Simulation models are based on the SIMAN language (Pegden et al., 1995). In order to experiment with different maintenance policies and to illustrates their effects on FMS performance, a case problem, as in figure 3 is considered. Table 1 shows the distance matrix for the FMS layout and Table 2 shows mixture of three different types of parts arriving on a cart, the sequence of operations, and the processing times on each machine. An automated guided vehicle (AGV) selects the parts and transports them to the machines according to processing requirements and the sequence. Each part type is operated on by a different sequence of machines. Completed parts are placed on a pallet and moved out of the system. The speed of the AGV is set at 175 feet/minute. Parts arrive to the system on pallets containing 4 parts of type 1, 2 parts of type 2, and 2 parts of type 3 every 2 hours. This combination was fixed in all simulation cases to eliminate the compounding effects of randomness in arriving parts on the comparisons of different maintenance policies. The FMS parameters are set based on values from an experimental system and previous studies.

One simulation model was developed for each of the six cases as: i) A fully reliable FMS (denoted by FR); ii) FMS with corrective maintenance policy only (CM); iii) FMS with block-based policy (BB); iv) FMS with age-based policy $(\mathrm{AB})$; v) FMS with opportunity-triggered maintenance policy (OP); and vi) FMS with conditional opportunity-triggered maintenance policy $(\mathrm{CO})$. Each 
simulation experiment was carried out for the operation of the FMS over a period of one month (20 working days or 9600 minutes). In the case of PM, it was assumed that a PM time of 30 minutes (or 15 minutes when combined with $\mathrm{CM}$ ) is added to 480 minutes at the end of each shift. Twenty simulation replicates are made and the average output rate during one month is determined. The output rate is then used to determine the FMS operational availability index for each policy. The output rate is calculated as the average of the sum of all parts of all types produced during the month. The fully reliable FMS demonstrates maximum possible output $\left(\mathrm{P}_{\mathrm{i}}\right)$ and is used as a base to compare other maintenance policies with $\mathrm{OAI}_{\mathrm{i}}=\mathrm{P}_{\mathrm{i}} / \mathrm{P}_{1}$.

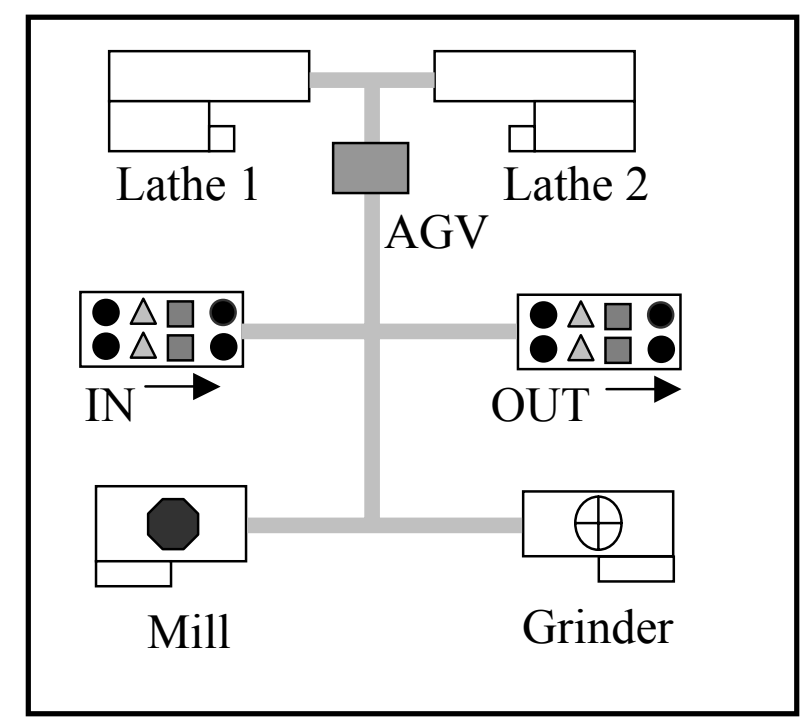

Figure 3. A flexible manufacturing system

\begin{tabular}{|c|c|c|c|c|c|}
\hline & In & Lathe & Mill & Grind & Out \\
\hline In & - & 100 & 75 & 100 & 40 \\
\hline Lathe & - & - & 150 & 175 & 155 \\
\hline Mill & - & - & - & 50 & 90 \\
\hline Grind & - & - & - & - & 115 \\
\hline Out & - & - & - & - & - \\
\hline
\end{tabular}

Table 1. Distance matrix (in feet). 


\begin{tabular}{|l|lll|}
\hline Part Type & Lathe(L) & Milling(M) & Grinding(G) \\
\hline 1 (L-M-G) & Norm(30,5) & Norm(15,3) & Unif(10,15) \\
2 (M-G-L) & Norm(25,8) & Tria(2,10,15) & Norm(10,2) \\
3 (G-L) & Unif (5,10) & & Norm(15,3) \\
\hline
\end{tabular}

Table 2. Processing time and operation sequences.

In the first simulation experiment, times between failures are assumed to be uniformly distributed between 0 and $\mathrm{T}$ for all machines with MTBF of $\mathrm{T} / 2$. Uniform distribution permits theoretical separation of chance-caused failures from wear-out failures. In the absence of any preventive maintenance, a machine can fail anytime from 0 to T. However, when PM is introduced, wear-out failures are eliminated; only the failures from chance causes remain, which have a constant hazard rate and exponential distribution with MTBF of T. In this experiment, the value of $\mathrm{T}$ is varied from 500 to 4000 minutes, in increments of 500 minutes. Repair time is assumed to be normal with mean 100 and standard deviation of 10 minutes for all machines. If PM is introduced on a machine, it is assumed that the PM is done at the end of each shift and it takes 30 minutes for each machine. If PM is triggered by the CM and done at this opportunity, PM time reduces to half, i.e., 15 minutes, since it is combined with the CM tasks. Mean production rate values are normalized with respect to fully reliable (FR) FMS values and converted into OAIs. These results are shown in figure 4. As it is seen from figure 4, performing CM alone without any PM is the worst policy of all. Observing all the policies in the figure, the best policy appears to be the opportunity triggered maintenance policy (OT). Between the age and block-based policies, the age-based policy (AB) performed better. Among all the policies with PM, block-based policy (BB) appears to be the worst policy.

As the MTBF increases, all the policies reach a steady state level with respect to operational availability, but the gap between them is almost the same at all levels of MTBF. In the case of CM only policy, the operational availability index sharply increases with the initial increase in MTBF from 500 to 1000. 


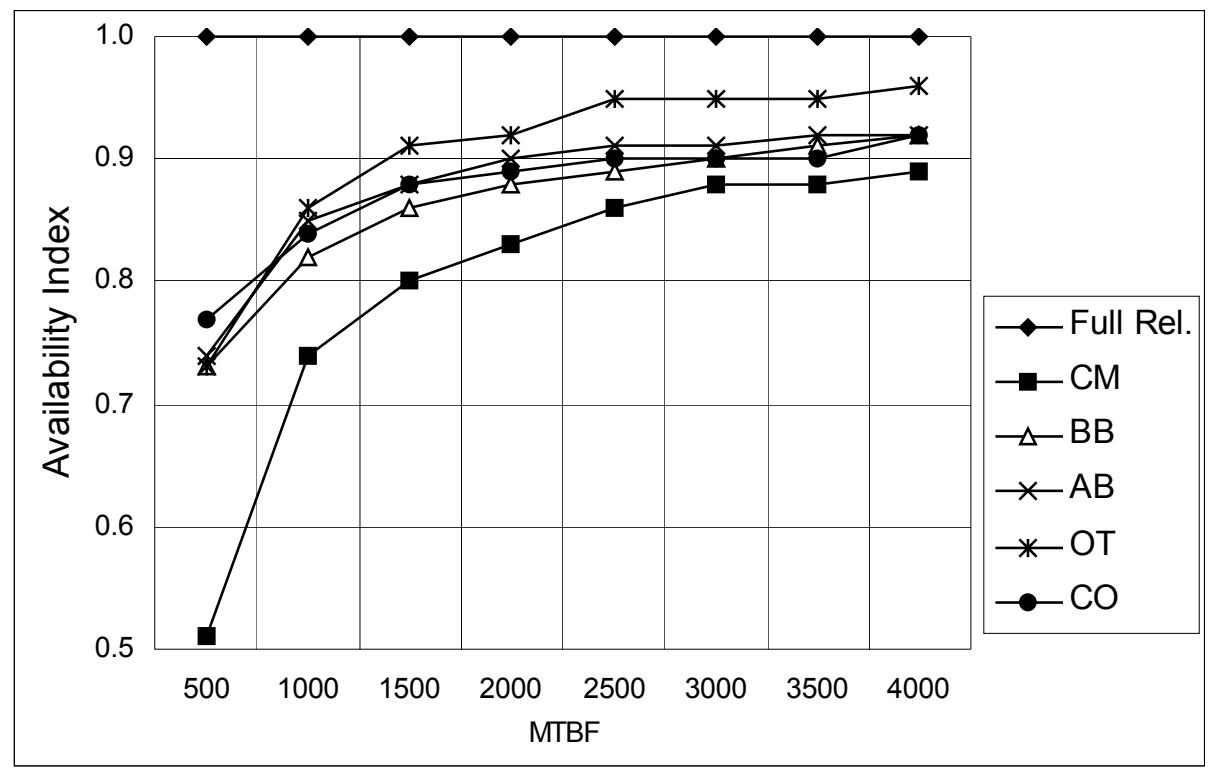

Figure 4. Operational availability index under different maintenance policies.

As indicated above, when PM is introduced, time between failures become exponential regardless of the type of initial distribution. Experiments with different distributions show that all distributions give the same performance results under the last four maintenance policies, which include some form of PM. However, FMS performance would differ under different failure distributions when a CM policy is implemented. This is investigated in the second experiment, which compares the effects of various time to failure distributions, including uniform, normal, gamma, Weibull, and triangular distributions, on FMS performance under the CM policy only. All of the FMS parameters related to operation times, repair, and PM times were kept the same as given in the first experiment. Only time to failure distributions and related parameters were changed such that MTBF was varied between 500 and 4000.

In the case of the gamma distribution, $\mathrm{E}(\mathrm{T})=\alpha \beta$. Thus, $\alpha=250$ and $\beta=2$ resulted in a MTBF of 500; $\alpha=750$ and $\beta=2$ resulted in a MTBF=1500; $\alpha=1250$ and $\beta=2$ resulted in a MTBF=2500; and $\alpha=2000$ and $\beta=2$ resulted in a $\mathrm{MTBF}=4000$, which are the same values specified in the second experiment for the normal distribution. For the Weibull distribution, which has $\mathrm{MTBF}=\mathrm{E}(\mathrm{T})=$ $\beta \Gamma(1 / \alpha) / \alpha$, two the parameters $\alpha$ (shape parameter) and $\beta$ (scale parameter) have to be defined. For example, if $\mathrm{MTBF}=500$ and $\alpha=2$, then, $500=\beta \Gamma(1 / \alpha) / \alpha$ 
$=\beta \Gamma(1 / 2) / 2$. Since $\Gamma(1 / 2)=\sqrt{ } \pi, \beta=1000 / \sqrt{ } \pi$. Thus, for $\mathrm{MTBF}=500, \beta=564.2$. Similarly, for $M T B F=1500, \beta=1692.2$, for $M T B F=2500, \beta=2820.95$, and for $M T B F=4000$, $\beta=4513.5$ are used. Triangular distribution parameters are also determined similarly as follows: $E(T)=(a+m+b) / 3$ and $V(T)=\left(a^{2}+m^{2}+b^{2}-m a-a b-m b\right) / 18$. Since the times between failures can be any value starting from zero, we let $a=0$ and $\mathrm{m}=\mathrm{b} / 3$ from the property of triangular distribution. $\mathrm{E}(\mathrm{T})=$ $(m+b) / 3=[b+b / 3] / 3=4 b / 9=4 m / 3$. In order to determine values of the parameters, we utilize these formula. For example, if $\mathrm{MTBF}=500$, then $500=4 \mathrm{~b} / 9$ and thus $b=4500 / 4=1125$ and $m=b / 3=1500 / 4=375$. Similarly, for $M T B F=1500, b=3375$ and $m=1125$. For $M T B F=2500, b=5625$ and $m=1875$. For $M T B F=4000, b=9000$ and $\mathrm{m}=3000$. Table 3 presents a summary of the related parameters.

\begin{tabular}{|l|l|l|l|l|}
\hline Distribution & \multirow{3}{*}{ MTBF } & \multicolumn{3}{|l|}{$\begin{array}{l}\text { Parameters that result in } \\
\text { the specified MTBF }\end{array}$} \\
\cline { 3 - 5 } & & $\alpha$ & $\beta$ & \\
\hline \multirow{4}{*}{ Gamma } & 500 & 250 & 2 & \\
\cline { 2 - 5 } & 1500 & 750 & 2 & \\
\cline { 2 - 5 } & 2500 & 1250 & 2 & \\
\cline { 2 - 5 } & 4000 & 2000 & 2 & \\
\hline Weibull & 500 & 2 & 564.2 & \\
\cline { 2 - 5 } & 1500 & 2 & 1692.2 & \\
\cline { 2 - 5 } & 2500 & 2 & 2820.95 & \\
\cline { 2 - 5 } & 4000 & 2 & 4513.5 & \\
\hline & MTBF & $\mathrm{a}$ & $\mathrm{b}$ & $\mathrm{m}$ \\
\hline & 500 & 0 & 1125 & 375 \\
\cline { 2 - 5 } & 1500 & 0 & 3375 & 1125 \\
\cline { 2 - 5 } & 2500 & 0 & 5625 & 1875 \\
\hline & 4000 & 0 & 9000 & 3000 \\
\hline
\end{tabular}

Table 3. Parameters of the distributions used in simulation.

Comparisons of five distributions, uniform, normal, gamma, Weibull, and triangular, with respect to $\mathrm{CM}$ are illustrated in figure 5, which plots the OAI values normalized with respect to fully reliable system using production rates. All of the distributions show the same trend of increasing OAI values, and thus production rates, with respect to increasing MTBF values. As it seen in figure 5, uniformly distributed time between failures resulted in significantly 
different FMS availability index as compared the other four distributions. This is because in a uniform distribution, which is structurally different from other distributions, probability of failure is equally likely at all possible values that the random variable can take, while in other distributions probability concentration is around the central value. The FMS performance was almost the same under the other four distributions investigated. This indicates that the type of distribution has no critical effects on FMS performance under CM policy if the distribution shapes are relatively similar.

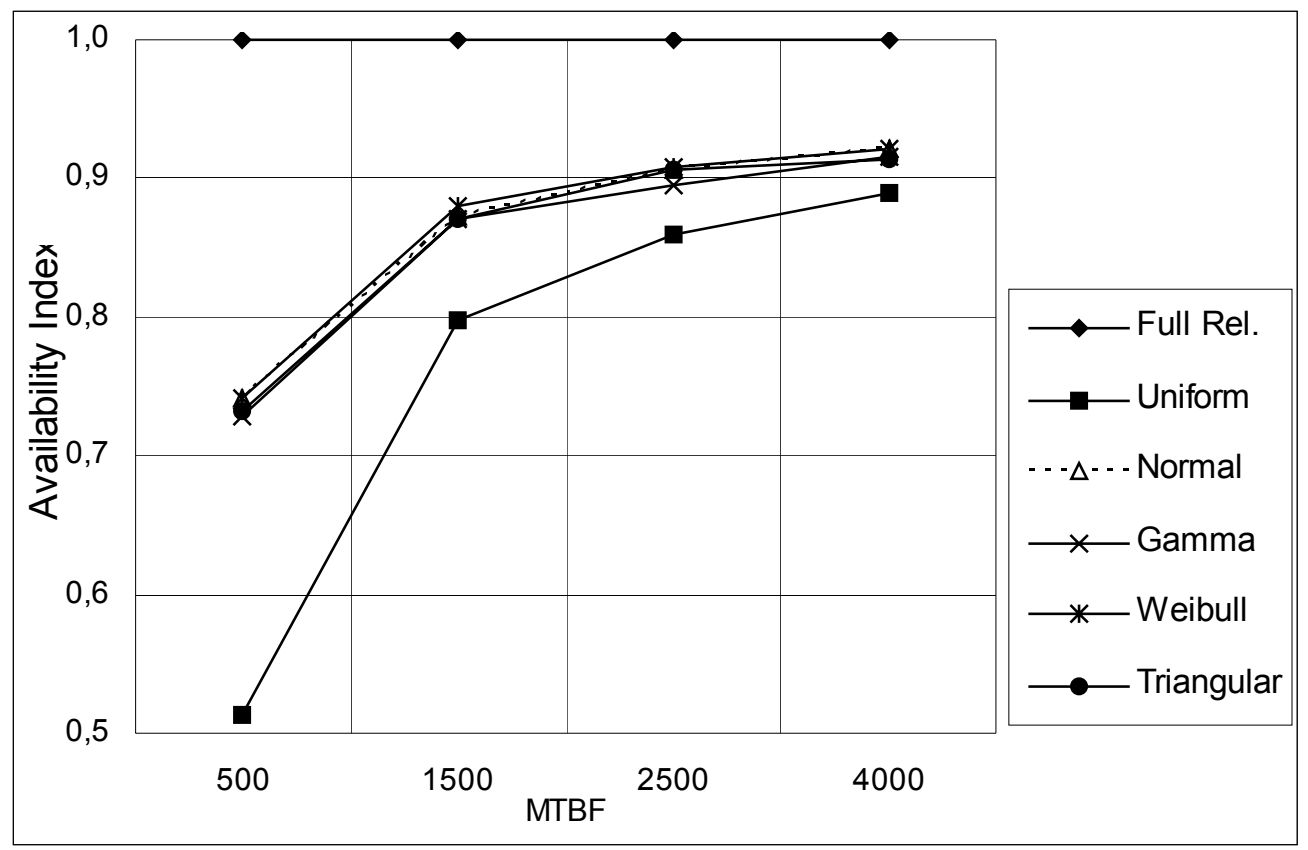

Figure 5. FMS OAI under various time to failure distributions and CM policy

The results of the analysis show that maintenance of any form has significant effect on the availability of the FMS as measured by its output rate. However, the type of maintenance applied is important and should be carefully studied before implementation. In the particular example studied, the best policy in all cases was the opportunity-triggered maintenance policy and the worst policy was the corrective maintenance policy. The amount of increase in system availability depends on the maintenance policy applied and the specific case studied. Implementation of any maintenance policy must also be justified by a detailed cost analysis. 
The results presented in this chapter show a comparative analysis of specified maintenance policies with respect to operational availability measured by output rate. Future studies can be carried out on the cost aspects of various policies. The best cost saving policy can be determined depending on the specified parameters related to the repair costs and the preventive maintenance costs. In order to do cost related studies, realistic cost data must be collected from industry. The same models developed and procedures outlined in this paper can be used with cost data. Other possible maintenance policies must be studied and compared to those presented in this study. Combinations of several policies are also possible within the same FMS. For example, while a set of equipment is maintained by one policy, another set could be maintained by a different policy. These aspects of the problem may also be investigated by the models presented.

\section{Analysis of the Effects of Maintenance Policies on Serial Lines}

Multi-stage discrete part manufacturing systems are usually designed along a flow line with automated equipment and mechanized material flow between the stations to transfer work pieces from one station to the next automatically. $\mathrm{CM}$ and PM operations on serial lines can cause significant production losses, particularly if the production stages are rigidly linked. In-process inventories or buffer storages are introduced to decouple the rigidly-linked machinery and to localize the losses caused by equipment stoppages. Buffer storages help to smooth out the effect of variation in process times between successive stations and to reduce the effects of CM and PM in one station over the adjacent stations. While large buffer capacities between stages result in excessive inventories and costs, small buffer capacities result in production losses due to unexpected and planned stoppages and delays. One of the major problems associated with the design and operation of a serial production system is the determination of the effects of maintenance activities coupled with certain buffer capacities between the stations. Reliability and productivity calculations of multi-stage lines with maintenance operations and intermediate storage units can be quite complex. Particularly, closed form solutions are not possible when different types of maintenance operations are implemented on the machines. Production line systems can take a variety of structures depending on the operational characteristics. Operation times can be stochastic or deterministic; stations can be reliable or unreliable; buffer capacities can be finite or infinite; 
production line can be balanced or unbalanced; and material flow can be considered as discrete or continuous. Depending on the type of line considered and the assumptions made, complexity of the models vary. The objective in modeling these systems is to determine line throughput rate and machine utilizations as a function of equipment failures, maintenance policies, and buffer capacities,. Optimum buffer allocation results in maximum throughput rate. Algorithms and models are developed for buffer allocation on reliable and unreliable production lines for limited size problems. While closed form analytical models or approximations are restricted by several assumptions, models that can be coupled with numerical evaluation or computer simulation are more flexible and allow realistic modeling.

In this chapter we present a discrete mathematical model, which is incorporated into a generalized iterative simulation procedure to determine the production output rate of a multi-stage serial production line operating under different conditions, including random failures with corrective and preventive maintenance operations, and limited buffer capacities. The basic principal of the discrete mathematical model is to determine the total time a part $n$ spends on a machine $i$, the time instant at which part $n$ is completed on machine $i$, and the time instant at which part $n$ leaves machine $i$. Figure 6 shows a multi-stage line with $m$ machines and $(m+1)$ intermediate buffer storages. Because each production machine is a highly complex combination of several instruments and working parts, it is assumed that more than one type of failure, which require different corrective actions, can occur on each machine and that each machine may receive more than one type of preventive maintenance actions. Effects of different maintenance policies on line production output rate are investigated.

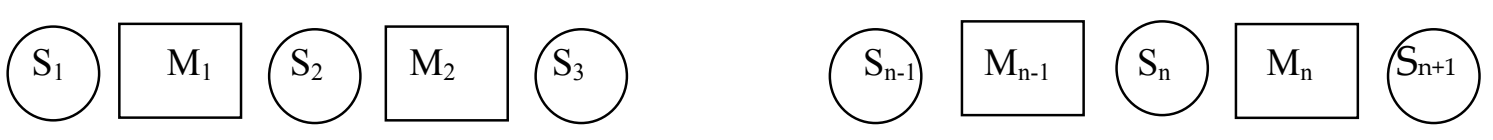

Figure 6. A Serial Production Flow Line with n Stations and n+1 Buffers

Storages $\mathrm{S}_{2}, \ldots \ldots, \mathrm{S}_{\mathrm{n}}$ are called intermediate storages, having finite capacity $\mathrm{Z}$, $\mathrm{i}=2, \ldots, \mathrm{m}$. However, the initial input and the final output storages, namely storages 1 and $m+1$, are assumed to have unlimited capacities. The following notation is used in the formulation: 
- $R_{i n}=$ Total duration of time that $n^{\text {th }}$ part stays on the $i^{\text {th }}$ machine not considering imposed stoppages due to maintenances or failures; $i=1,2, \ldots . ., m$.

- $m=$ Number of machines on the line.

- $P_{i j n}=$ Duration of preventive maintenance of $j^{\text {th }}$ type on the $i^{\text {th }}$ machine after machining of $n^{\text {th }}$ part is completed; $j=1,2, \ldots \ldots, n p_{i}$

- $n p_{i}=$ Number of preventive maintenance types performed on machine $i$

- $t_{i n}=$ Machining time for part $n$ on machine $i$. This time can be assumed to be independent of $n$ in the simulation program.

- $r_{i j n}=$ Repair time required by $i^{\text {th }}$ machine for correction of $j^{\text {th }}$ type of failures which occur during the machining of $n^{\text {th }}$ part; $j=1,2, \ldots \ldots, n f_{i}$

- $n f_{i}=$ Number of failure types which occur on machine $i$.

- $C_{i n}=$ Instant of time at which machining of $n^{\text {th }}$ part is completed on $i^{\text {th }}$ machine.

- $D_{\text {in }}=$ Instant of time at which $n^{\text {th }}$ part departs from the $i^{\text {th }}$ machine.

- $D_{0 n}=$ Instant of time at which $n^{\text {th }}$ part enters the $1^{\text {st }}$ machine.

- $W_{\text {in }}=$ Instant of time at which $i^{\text {th }}$ machine is ready to process $n^{\text {th }}$ parts.

A part stays on a machine for two reasons: Either it is being machined or the machine is under corrective maintenance because a breakdown has occurred during machining of that part. $R_{i n}$, which is the residence time of the $n^{\text {th }}$ part on the $i^{\text {th }}$ machine, without considering imposed stoppages for corrective maintenance, is given as follows:

$$
R_{i n}=t_{i n}+\sum_{j=1}^{n f_{i}} r_{i j n}
$$

The duration of total preventive maintenance, $P_{i n}$, performed on the $i^{\text {th }}$ machine after completing the $n^{\text {th }}$ part, is equal to the total duration of all types of preventive maintenances, $P_{i j n}$, that must be started after completion of $n^{\text {th }}$ part as:

$$
P_{i n}=\sum_{j=1}^{n p_{i}} P_{i j n}
$$

Each buffer $B_{i}$ is assumed to have a finite capacity $z_{i}, i=2,3, \ldots \ldots, m$. The discrete mathematical model of serial line consists of calculating part completion times, $C_{i n}$, and part departure times, $D_{i n}$, in an iterative fashion. 


\subsection{Determination of Part Completion Times}

Machining of part $n$ cannot be started on machine $i$ until the previous part, $n-1$, leaves machine $i$ and until all the required maintenances, if necessary, are performed on machine $i$. Therefore the time instant at which $i^{\text {th }}$ machine is ready to begin the $n^{\text {th }}$ part, denoted by $W_{i n}$, is given by the following relation:

$$
W_{\text {in }}=\max \left[D_{i, n-1}, C_{i, n-1}+P_{i, n-1}\right]
$$

If $D_{i-1, n}<W_{i n}$, then the $n^{\text {th }}$ part must wait in storage buffer $S_{i}$, since it has left machine $i-1$ before machine $i$ is ready to accept it. Therefore, machining of part $n$ on machine $i$ will start at instant $W_{i n}$. If however, $D_{i-1, n} \geq W_{i n}$, then machining of the $n^{\text {th }}$ part on the $i^{\text {th }}$ machine can start immediately after $D_{i-1, n}$. Considering both cases above, starting time of the $n^{\text {th }}$ part to be machined on the $i^{\text {th }}$ machine is:

$$
\max \left[D_{i-1, n,} D_{i, n-1,} C_{i, n-1}+P_{i, n-1}\right]
$$

Since the $n^{\text {th }}$ part will stay on machine $i$ for a period of $R_{\text {in }}$ time units, its machining will be completed by time instant $C_{\text {in }}$ given by:

$$
C_{i n}=\max \left[D_{i-1, n}, D_{i, n-1}, C_{i, n-1}+P_{i, n-1}\right]+R_{i n}
$$

Where

$$
i=2,3, \ldots \ldots, m \text { and } C_{1 n}=\max \left[D_{1, n-1}, C_{1, n-1}+P_{1, n-1}\right]+R_{1 n}
$$

Then,

$$
D_{0 n}<\max \left[D_{1, n-1,} C_{1, n-1}+P_{1, n-1}\right]
$$

assuming there are always parts available in front of machine 1. 


\subsection{Determination of Part Departure Times}

The time instant at which $n^{\text {th }}$ part leaves the $i^{\text {th }}$ machine, $D_{i n}$, is found by considering two cases.

Let $k=n-z_{i+1}-1$. Then, in the first case:

$$
C_{i, n}<\max \left[D_{i+1, k}, C_{i+1, k}+P_{i+1, k}\right]
$$

which indicates that the $n^{\text {th }}$ part has been completed on the $i^{\text {th }}$ machine before machining of the $\left(n-z_{i+1}\right)^{\text {th }}$ part has started on the $(i+1)^{\text {th }}$ machine. Since storage $i+1$, which is between machine $i$ and $i+1$ and has capacity $z_{i+1}$, is full and machine $i$ has completed the $n^{\text {th }}$ part, the $n^{\text {th }}$ part may leave the $i^{\text {th }}$ machine only at the instant of time at which the $\left(n-z_{i+1}\right)^{\text {th }}$ part of the $(i+1)^{\text {th }}$ machine has started machining. Therefore,

$$
D_{i, n}=\max \left[D_{i+1, k}, C_{i+1, k}+P_{i+1, k}\right]
$$

In the second case:

$$
C_{i, n}>\max \left[D_{i+1, k}, C_{i+1, k}+P_{i+1, k}\right]
$$

which indicates that, at the instant $C_{i, n}$ there are free spaces in buffer $S_{i+1}$ and therefore part $n$ can leave machine $i$ immediately after it is completed; that is, $D_{i, n}=C_{i, n}$ holds under this case. Considering both cases above, we have the following relations for $D_{i, n}$ :

$$
\begin{gathered}
D_{i, n}=C_{i, n} \quad \text { if } n \leq z_{i+1}+1, \\
D_{i, n}=\max \left[C_{i, n}, D_{i+1, k}, C_{i+1, k}+P_{i+1, k}\right]
\end{gathered}
$$

if $n>z_{i+1}+1 ; \quad i=1,2,3, \ldots . ., m-1$ and $k=n-z_{i+1}-1$.

Since the last stage has infinite space to index its completed parts,

$$
D_{m, n}=C_{m, n}
$$


The simulation model, which is based on discrete mathematical model, can iteratively calculate $C_{i, n}$ and $D_{i, n}$ from which several line performance measures can be computed. Performance measures estimated by the above iterative computational procedures are: (i) Average number of parts completed by the line during a simulation period, $T_{\text {sim }}$; (ii) Average number of parts completed by each machine during the time, $T_{\text {sim }}$; (iii) Percentage of time for which each machine is up and down; (iv) Imposed, inherent and total loss factors for each machine; (v) Productivity improvement procedures.

In addition to the variables described for the discrete model in previous section, the simulation model can allow several distributions, including: exponential, uniform, Weibull, normal, log normal, Erlang, gamma, beta distributions and constant values to describe failure and repair times. After the production line related parameters and all data are entered into the simulator and necessary initializations are carried out by the program, iterative analysis of the production line is performed through the discrete mathematical model. The iterative analysis provides one simulation realization of the production line for a specified period of simulation time $\left(T_{\operatorname{sim}}\right)$. It basically calculates iteratively the time instant at which each part enters a machine, duration of its stay, and the time it leaves the machine. This is continued until, for example one shift is completed. The results of each iterative simulation are then utilized with statistical tests to determine if the specified conditions are met to stop the number of simulation iterations. If the conditions are not met, simulation iterations are continued with further runs. For each simulation realization, calculations of $R_{i, n}, C_{i, n}$ and $D_{i, n}$ are performed based on the need for repair or preventive maintenance operations as the parts flow through the system.

\subsection{Statistical Analysis and Determination of Need for More Realizations}

Reliable results cannot always be obtained from a single simulation realization. Therefore, additional runs have to be performed and the results tested statistically until the error in the line production rate is less than an epsilon value with a probability, both of which are predefined. This is accomplished as follows:

Let $N_{i}=$ number of parts produced by the production line during the $i^{\text {th }}$ simulation run. $N_{i}$ is a random variable which approaches normal distribution as $\mathrm{t} \rightarrow \infty$; that is, as the simulation time increases for ach realization, the sample random variable $N_{i}$ approaches to an asymptotic normal distribution. The 
mean value of $N_{i}, \bar{N}$, and its variance $V(N)$ are given by $\bar{N}=\sum_{i=1}^{n}\left(N_{i}\right) / n$ and $V(N)=\sum_{i=1}^{n}\left(N_{i}-\bar{N}\right)^{2} /(n-1)$, where $n$ represents the number of runs. The average line production rate, $\bar{Q}$, which is the average output rate per unit of time, is given by $\bar{Q}=\bar{N} / T_{\text {sim }}$ where $T_{\text {sim }}$ is the simulation time for each realization, given in minutes. The quantity $\bar{Q}$ is the average line production rate in parts/minute. The variance of $\bar{Q}, \quad V(\bar{Q}), \quad$ is determined by $V(\bar{Q})=V\left(\bar{N} / T_{\text {sim }}\right)=V(\bar{N}) / T_{\text {sim }}^{2}=V(N) / n\left(T_{\text {sim }}\right)^{2}$, since $V(\bar{N})=V(N) / n$. The standard deviation of the average production rate, $\bar{Q}$, is $\sqrt{V(\bar{Q})}$ and the ratio of its standard deviation to its mean is expressed as by: $\sqrt{V(\bar{Q})} / \bar{Q}=\left[\sqrt{V(N) / n T_{\text {sim }}}\right] /\left[\bar{N} / T_{\text {sim }}\right]=[\sqrt{V(N)}] /[\bar{N} \sqrt{n}]=[\sqrt{V(N) / n}] / \bar{N}$. Since the number of parts $N_{i}$ produced by the production line during a simulation period $T_{\mathrm{sim}}$ approaches the normal distribution, one can determine a confidence interval for $\bar{N}$ and $\bar{Q}$ using the normal distribution. $\operatorname{Pr}\left[\frac{N-\bar{N}}{\sqrt{V(N)}}<x\right]=\frac{1}{\sqrt{2 \pi}} \int_{-\infty}^{x} e^{-z^{2} / 2} d z$. The value of $\bar{N}$ is contained, with probability $1-\alpha$, in the interval given by $\operatorname{Pr}\left[-Z_{\alpha / 2}<\frac{N-\bar{N}}{\sqrt{V(N)}}<Z_{\alpha / 2}\right]=1-\alpha$. Since the mean output rate, $\bar{Q}$, is given by $\bar{Q}=\bar{N} / T_{\text {sim }}$, one can conclude that $\bar{Q}$ is normally distributed, as are $N$ and $\bar{N}$. Therefore, a confidence interval for the actual mean output rate $\overline{\bar{Q}}$ would be given by $\operatorname{Pr}\left[-Z_{\alpha / 2}<\frac{\bar{Q}-\overline{\bar{Q}}}{\sqrt{V(\bar{Q})}}<Z_{\alpha / 2}\right]=1-\alpha$ or by $\operatorname{Pr}\left[\bar{Q}\left(1-Z_{\alpha / 2} \sqrt{V(\bar{Q})} / \bar{Q}\right)<\overline{\bar{Q}}<\bar{Q}\left(1+Z_{\alpha / 2} \sqrt{V(\bar{Q})} / \bar{Q}\right)\right]=1-\alpha$

$$
\operatorname{Pr}\left[1-\frac{Z_{\alpha / 2} \sqrt{V(\bar{Q})}}{\bar{Q}}<\frac{\overline{\bar{Q}}}{\bar{Q}}<1+\frac{Z_{\alpha / 2} \sqrt{V(\bar{Q})}}{\bar{Q}}\right]=1-\alpha
$$

Our aim is to have an estimated output rate, $\bar{Q}$, as close to the actual mean output rate $\overline{\bar{Q}}$ as possible. To achieve this, $Z_{\alpha / 2} \sqrt{V(\bar{Q})} / \bar{Q}$ is minimized by obtaining more runs. As this value gets closer to $0, \bar{Q} \rightarrow \overline{\bar{Q}}$ with probability $1-\alpha$. An $\varepsilon$ value is entered by the user; the simulation program calculates $Z_{\alpha / 2} \sqrt{V(\bar{Q})} / \bar{Q}$ after each iteration; compares this quantity with $\varepsilon$ and terminates the program if it is less than $\varepsilon$. If it is not less than $\varepsilon$ after a maximum number of iterations entered by the user, the program is still terminated to avoid excessive computation time. However, the results may not be as reliable. 


\subsection{Productivity Improvement Procedure}

Operational characteristics, such as machining or operation times, equipment failures, corrective and preventive maintenance activities, and intermediate buffer capacities have significant effects on the production line efficiency. Assessment of the operational efficiency of an automated manufacturing line with storage units by computer simulation permits one to determine various possible parameters and dependent variables which have the most significant effects on productivity. Estimation indices are obtained for such variables as the total, inherent, and imposed relative time losses due to failures and stoppages for each machine. These variables are obtained by employing failure and repair times and nominal and relative production rates for each machine. These terms are defined as follows:

$Q_{n}(i)=60 / t(i)$ is the normal productivity of machine $i$, where $t(i)$ is the cycle time for machine $i ; Q_{r}(i)=60 \bar{N} / T_{\text {sim }}$ is the relative productivity of machine $i$; $K_{\text {loss }}(i)=1-Q_{r}(i) / Q_{n}(i)$ is the total loss factor of machine $i$; $K_{\mathrm{inh}}(i)=1-\bar{t}_{r}(i) /\left[\bar{t}_{r}(i)+\bar{t}_{f}(i)\right]$ is inherent loss factor of machine $i$; and $K_{\text {imp }}(i)=K_{\text {loss }}(i)-K_{\text {inh }}(i)=1-Q_{r}(i) / Q_{n}(i)-\bar{t}_{r}(i) /\left[\bar{t}_{r}(i)+\bar{t}_{f}(i)\right]$ is the imposed loss factor for machine $i, \quad i=1,2, \ldots . ., m$. The terms $\bar{t}_{f}(i)$ and $\bar{t}_{r}(i)$ are mean times to failure and repairs, respectively of machine $i$. After determining these loss factors, the program can compare total loss factors for all machines. The machine or stage which has the highest total loss factor is then chosen for improvement. This machine's imposed and inherent losses are compared.

The following two suggestions are made.

(i) If $K_{\operatorname{imp}}(i)>K_{\operatorname{inh}}(i)$, it is suggested that the capacity of storages immediately preceding and succeeding machine $i$ with highest total loss factor should be increased. Reliability and productivity of machine $i-1$ and machine $i+1$ should also be increased.

(ii) If $K_{\text {inh }}(i)>K_{\text {imp }}(i)$, stoppages are mainly caused by inherent failures, that is breakdowns. Therefore, the reliability of machine $i$ should be increased by PM or its mean repair time should be decreased in order to gain improvement in total productivity. After the changes are made, simulation should be repeated to see the effects of the proposed changes in the line design. 


\subsection{Case Problem and Simulation Results}

In order to illustrate the model developed above and to demonstrate the effects of maintenance operations on the productivity of serial production lines with intermediate buffers, two case problems are considered as follows.

Case problem 1: A balanced serial production line with 5 stations is considered. Operation times are 1.25 minutes on all stations; Number of failure types on each equipment is 2 failures; Distributions of time to failure and related parameters are Uniform $(0,120)$ and Uniform $(0,180)$ with means of 60 and 90 minutes respectively; Distributions of repair times and related parameters are Normal $(5,1)$ and Normal $(7,1.5)$; Buffer storage capacities between stations are varied from 1 to 10 . When a preventive maintenance is implemented on the line, wear out failures are eliminated and only random failures, with constant failure rates, remain. Time between failures extend from uniform to exponential as explained in section 2.4.

Average line output rate $($ parts $/ \mathrm{min})=0.674104$

Standard deviation of line output rate $=0.0031194163$

\begin{tabular}{|c|c|c|c|c|c|}
\hline $\begin{array}{c}\text { Machine } \\
\text { Number }\end{array}$ & $\begin{array}{c}\text { Total } \\
\text { Parts Pro- } \\
\text { duced }\end{array}$ & $\begin{array}{c}\text { Relative } \\
\text { Production } \\
\text { Rate }\end{array}$ & $\begin{array}{c}\text { Nominal } \\
\text { Production } \\
\text { Rate }\end{array}$ & $\begin{array}{c}\text { Imposed } \\
\text { Loss Fac- } \\
\text { tor }\end{array}$ & $\begin{array}{c}\text { Inherent } \\
\text { Loss Fac- } \\
\text { tor }\end{array}$ \\
\hline 1 & 8102.250 & 40.515 & 48.000 & 0.081 & 0.075 \\
\hline 2 & 8099.750 & 40.508 & 48.000 & 0.083 & 0.073 \\
\hline 3 & 8096.250 & 40.484 & 48.000 & 0.080 & 0.077 \\
\hline 4 & 8089.750 & 40.456 & 48.000 & 0.084 & 0.074 \\
\hline 5 & 8089.250 & 40.448 & 48.000 & 0.084 & 0.073 \\
\hline
\end{tabular}

Machine 5 has the maximum total loss factor.

Down time is mainly imposed: increase the capacity of storage adjacent to this machine, also increase reliability by PM; increase productivity of adjacent machines; reduce the CM times and try simulation again.

Maximum iteration is reached at 75.

Table 4. Iterative Simulation Output Results for Production Line Case 1 
Two types of PM with intervals of 120 minutes and 180 minutes (corresponding to 96 parts and 144 parts) are assumed to be implemented to eliminate wear out failures; PM times are 2.5 and 3.5 time units. Time to failure distributions change to exponential with mean time to failures of 120 and 180 minutes. Distributions of repair times and related parameters are Normal $(5,1)$ and Normal $(7,1.5)$. Buffer storage capacities are again varied between 1 and 10 units. Parameters related to statistical tests were set as follows: $\alpha=0.05$; $Z_{\alpha / 2}=1.96 ; \varepsilon=0.001$, maximum number of iterations $=200$; and production simulation time was 12,000 minutes. Table 4 shows one output example for the balanced line case under CM\&PM policy when maximum buffer capacity of 10 units are allowed between the stations. Average line output rate obtained is 0.674104 parts/minute. Station production rates, loss factors, and suggestion for improvements are also shown in the table. Related results obtained for all other cases of buffer sizes are summarized in Figure 7.

The effects of CM only policy and the policy of implementing PM with CM (CM and $\mathrm{PM})$, under different buffer capacities are illustrated in the figure. An increase in production rate is achieved due to PM implementation for all cases of buffer capacities. The increase in production rate levels off as the buffer capacity is increased.

Case Problem 2: In addition to the balanced line case as shown in figure 7, three unbalanced cases, with a bottleneck station at the beginning, at the middle, and at the end of the line, are considered. Figure 8 shows the results for three unbalanced line cases under $\mathrm{CM}$ as well as $\mathrm{CM}$ with PM policies. It is assumed that a bottleneck station with operation time of 1.50 minutes is located at the beginning (designated as Bottleneck at Start=BS in figure 8), in the middle (Bottleneck in Middle=BM), or at the end of the line (Bottleneck at End=BE). As it is seen in the figure, all CM \& PM cases result in higher production rate than $C M$ only cases. Figure 8 also shows that when the bottleneck station is in the middle of the line, production rate is less than the cases of bottleneck being at the beginning or at the end of the line. These two last cases result in almost equal production rates as can be seen in the figure. The discrete model and the related program can also be used to perform an exhaustive search to find the optimum allocation of total fixed buffer capacity to the stages to maximize the line production rate. 


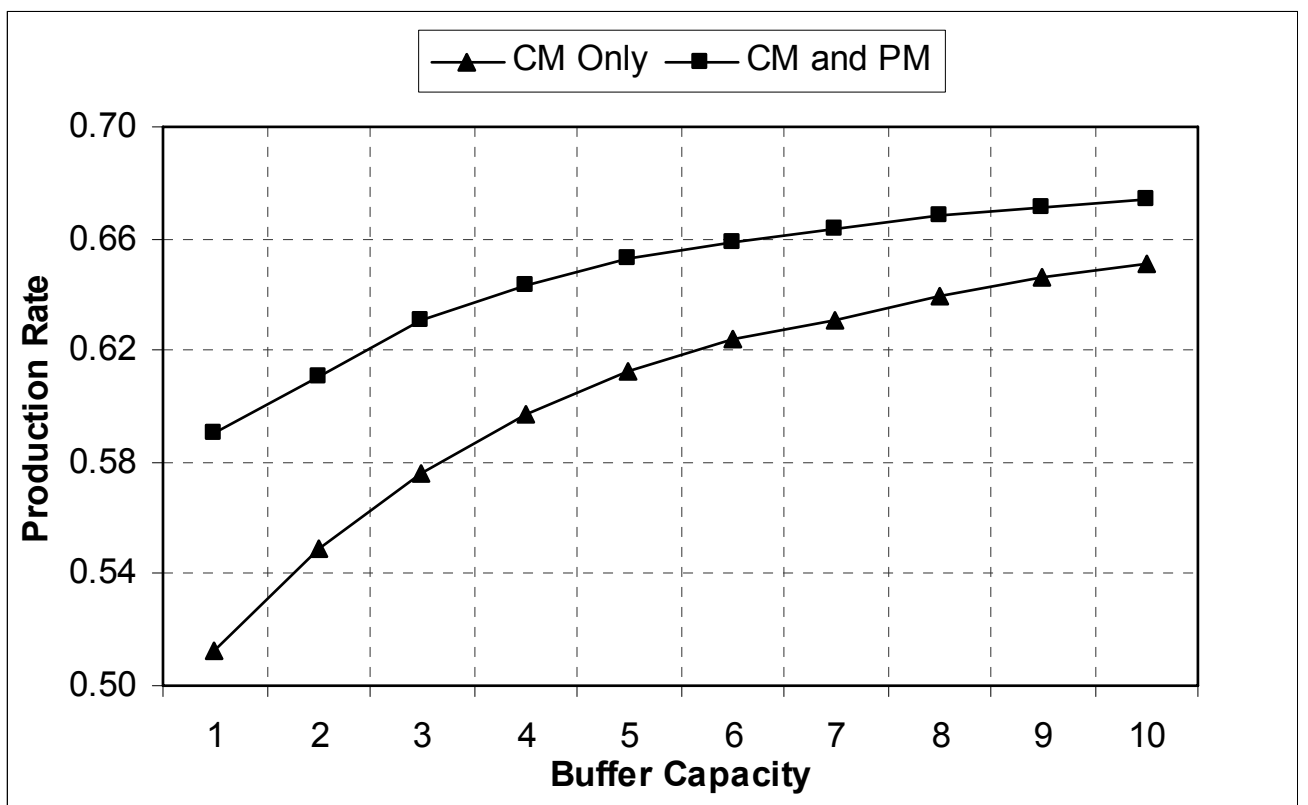

Figure 7. Comparison of CM policy with CM \& PM policy for the balanced line

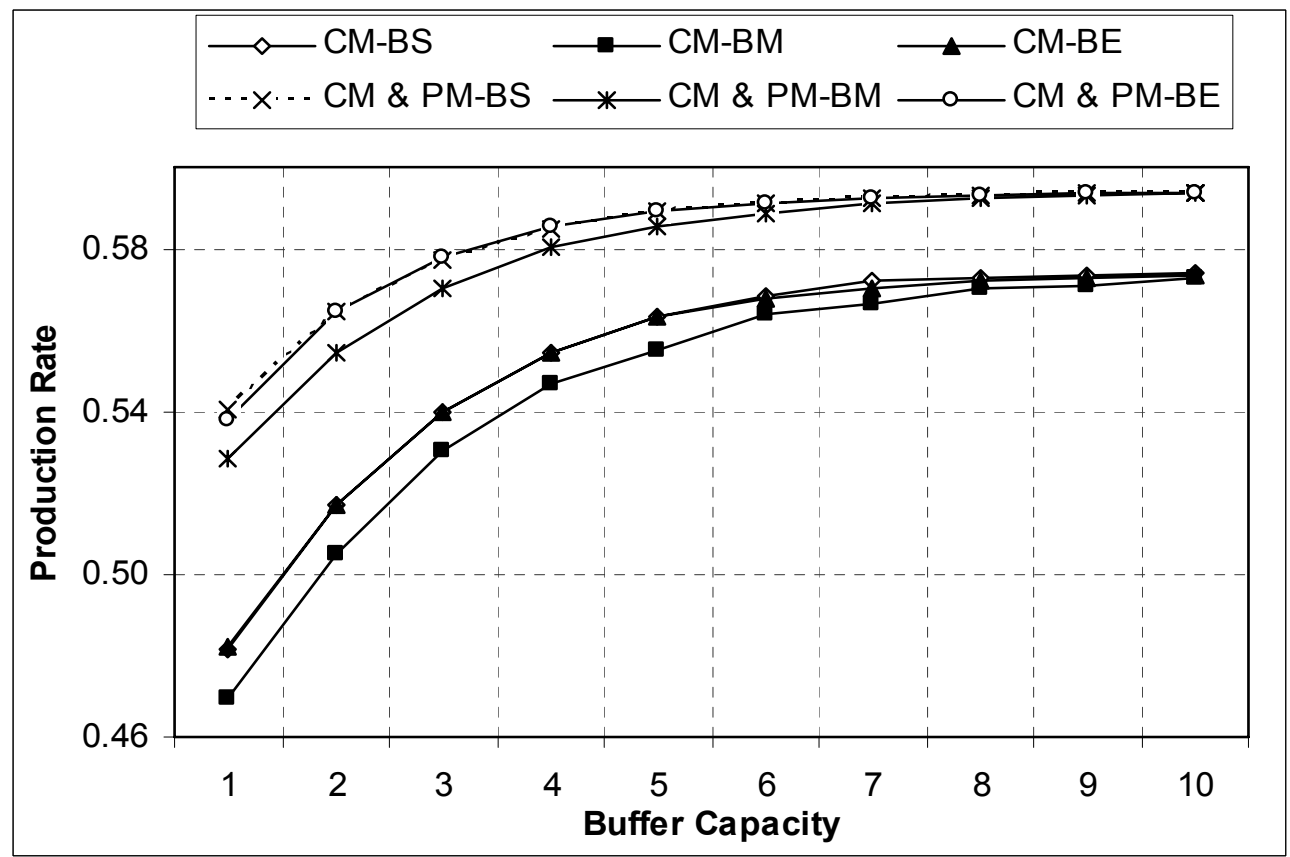

Figure 8. Comparison of CM policy with CM \& PM policy for unbalanced line 


\section{Concluding Remarks}

This chapter has presented some basic concepts in maintenance modeling for production systems. Mathematical models are developed for separation of different types of failure rates to evaluate effects of maintenance on equipment productivity. The models were first applied to a FMS through simulation and the results were discussed. It is found that PM of any type results in higher productivity than CM only. However, depending on the type of system considered, some PM policies perform better than others. The best policy must be determined by the analysis of the given system using the tools presented.

In order to analyze the effects of maintenance on the performance of serial production lines, a discrete mathematical model and an iterative computer simulation are developed for multi-stage production lines. The model allows several types of failures and maintenances to be incorporated into the analysis. Based on the discrete model, simulation approach incorporates a three-stage procedure which allows the user to enter a set of data describing the system under study, simulates the system until selected statistical criteria are satisfied and obtains output results. Specific recommendations for productivity increase can be applied until a satisfactory production output is achieved. The model is applied to the cases of balanced and unbalanced lines and the effects of PM are investigated. When PM was implemented in addition to $\mathrm{CM}$, line productivity was significantly increased. The discrete model and the iterative simulation procedure proved to be very useful in estimating the production line productivity for complex realistic production systems. It allows the line designer or operation managers to evaluate the effects of storage-unit capacity and repair/maintenance policies on line productivity. As a future study, the suggested iterative model can be incorporated into an interactive visual computer software to be effectively utilized by design engineers and operation managers.

\section{Acknowledgement}

This chapter was prepared based on a research that was supported by Kuwait University Research Administration under the grant number EI02/03. 


\section{References}

Albino, V., Carella, G., and Okogbaa, O. G. (1992). Maintenance Policies in Just-in-time Manufacturing Lines. International Journal of Production Research, Vol. 30, No. 2, 369-382.

Al-Najjar, B., Alsyouf, I. (2003). Selecting the Most Efficient Maintenance Approach Using Fuzzy Multiple Criteria Decision Making. International Journal of Production Economics, Vol. 84, No. 1, 85-100.

Ben-Daya, M. and Makhdoum, M. (1998). Integrated Production and Quality Model Under Various Preventive Maintenance Policies. Journal of the Operational Research Society, Vol. 49, 840-853.

Boukas, K. and Haurie, A. (1990). Manufacturing Flow Control and Preventive Maintenance: A Stochastic Control Approach. IEEE Transactions on Automatic Control, Vol. 35, No. 9, 1204-1031

Castro, H. F. D. and Cavalce, K. L.(2006). Maintenance Resources Optimization Applied to a Manufacturing System. Reliability Engineering and System Safety, Vol. 91, 413-420.

Chan, F. T. S., Lau, H. C. R., Ip, R. W. L., Chan, H. K., and Kong, S. (2005). Implementation of Total Productive Maintenance: A Case Study. International Journal of Production Economics, Vol. 95, No. 1, 71-94.

Cho, I. D. and Parlar, M. (1991). A Survey of Maintenance Models for Multiunit Systems. European Journal of Operational Research, Vol. 51, 1-23.

Creehan, K. D. (2005). Establishing Optimal Maintenance Practices in a Traditional Manufacturing Environment. Journal of the Chinese Institute of Industrial Engineers, Vol. 22, No. 1, 11-18.

Dekker, R. and Smeitnik, E. (1994). Preventive Maintenance at Opportunities of Restricted Duration. Naval Research Logistics, Vol. 41, 335-353.

Dekker, R.(1996). Applications of Maintenance Optimization Models: A Review and Analysis. Reliability Engineering and System Safety. Vol. 51, 229240.

Gupta, Y. P., Somers, T. M., and Grau, L. (1998). Modeling the Interrelationship Between Downtimes and Uptimes of CNC Machines. European Journal of Operational Research, Vol. 37, 254-271.

Kennedy, W. J. (1987). Issues in the Maintenance of Flexible Manufacturing Systems. Maintenance Management International, Vol. 7, 43-52

Kyriakidis, E. G. and Dimitrakos, T. D. (2006). Optimal Preventive Maintenance of a Production System with an Intermediate Buffer. European Journal of Operational Research, Vol. 168, 86-99. 
Levitin, G. and Meizin, L. (2001). Structure optimization for continuous production systems with buffers under reliability constraints. International Journal of Production Economics, Vol. 70, 77-87.

Lin, C., Madu, N.C., and Kuei C. (1994). A Closed Queuing Maintenance Network for a Flexible Manufacturing System. Microelectronics Reliability, Vol. 34, No. 11, 1733-1744.

McKone, K. and Wiess, E. (1998). TPM: Planned and Autonomous Maintenance: Bridging the Gap Between Practice and Research. Production an Operations Management, Vol. 7, No. 4, 335-351.

Mobley, R. K. (1990). An Introduction to Predictive Maintenance. Van Nostrand Reinhold. New York.

Papadopoulos, H. T. and Heavey, C. (1996). Queuing Theory in Manufacturing Systems Analysis and Design: A Classification of Models for Production and Transfer Lines. European J. of Operational Research, Vol. 92, 1-27.

Pegden, C.D., Shannon, R.E., and Sadowski, R. P. (1995). Introduction to Simulation Using SIMAN, $2^{\text {nd }}$ edition, McGraw Hill, New York.

Pintelon, L. M. and Gelders, L. F. (1992). Maintenance Management Decision Making. European Journal of Operational Research, Vol. 58, 301-317.

Savsar, M. and Biles, W. E. (1984). Two-Stage Production Lines with Single Repair Crew. International J. of Production Res., Vol. 22, No.3, 499-514.

Savsar, M. (1997a). Modeling and Analysis of a Flexible Manufacturing Cell. Proceedings of the $22^{\text {nd }}$ International Conference on Computers and Industrial Engineering, December 20-22, Cairo, Egypt, pp. 184-187.

Savsar, M. (1997b) Simulation Analysis of Maintenance Policies in Just-In-Time Production Systems. International Journal of Operations \& Production Management, Vol. 17, No. 3, 256-266

Savsar, M. (2000). Reliability Analysis of a Flexible Manufacturing Cell. Reliability Engineering and System Safety, Vol. 67, 147-152

Savsar, M. and Youssef, A. S. (2004). An Integrated Simulation-Neural Network Meta Model Application in Designing Production Flow Lines. WSEAS Transactions on Electronics, Vol. 2, No. 1, 366-371.

Savsar, M. (2005a). Performance Analysis of FMS Operating Under Different Failure Rates and Maintenance Policies. The International Journal of Flexible Manufacturing Systems, Vol. 16, 229-249.

Savsar, M. (2005b) Buffer Allocation in Serial Production Lines with Preventiveand Corrective Maintenance Operations. Proceedings of Tehran Interna- 
tional Congress on Manufacturing Engineering (TIMCE'2005), December 1215, 2005, Tehran, Iran.

Savsar, M. (2006). Effects of Maintenance Policies on the Productivity of Flexible Manufacturing Cells. Omega, Vol. 34, 274-282.

Sheu, C. and Krajewski, L.J. (1994). A Decision Model for Corrective Maintenance Management. International Journal of Production Research, Vol. 32, No. 6, 1365-1382.

Sun, Y. (1994). Simulation for Maintenance of an FMS: An Integrated System of Maintenance and Decision-Making. International Journal of Advance Manufacturing Technology, Vol. 9, 35-39.

Valdez-Flores, C. and Feldman, R.M. (1989). A Survey of Preventive Maintenance Models for Stochastically Deteriorating Single-Unit Systems. Naval Research. Logistics, Vol. 36, 419-446.

Vatn, J., Hokstad, P., and Bodsberg, L. (1996). An Overall Model for Maintenance Optimization. Reliability Engineering and System Safety, Vol. 51, 241257

Vineyard M. L. and Meredith J. R. (1992). Effect of Maintenance Policies on FMS Failures. Int. J. of Prod. Research, Vol. 30, No. 11, 2647-2657.

Vouros, G. A., Vidalis, M. I., Papadopoulos, H. T. (2000). A Heuristic Algorithm for Buffer Allocation in Unreliable Production Lines. International Journal of Quantitative Methods, Vol. 6, No. 1, 23-43.

Waeyenbergh, G. and Pintelon, L. (2004). Maintenance Concept Development: A Case Study. International J. of Production Economics, Vol. 89,395-405. 


\section{Manufacturing}

the Future

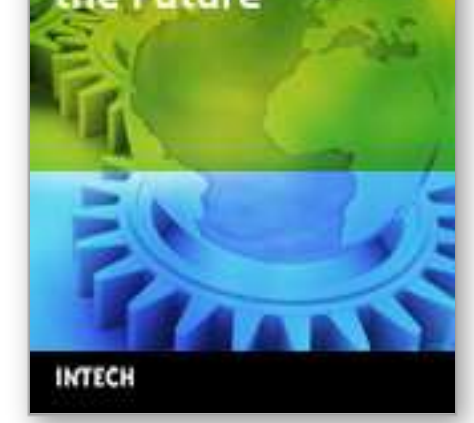

\section{Manufacturing the Future}

Edited by Vedran Kordic, Aleksandar Lazinica and Munir Merdan

ISBN 3-86611-198-3

Hard cover, 908 pages

Publisher Pro Literatur Verlag, Germany / ARS, Austria

Published online 01, July, 2006

Published in print edition July, 2006

The primary goal of this book is to cover the state-of-the-art development and future directions in modern manufacturing systems. This interdisciplinary and comprehensive volume, consisting of 30 chapters, covers a survey of trends in distributed manufacturing, modern manufacturing equipment, product design process, rapid prototyping, quality assurance, from technological and organisational point of view and aspects of supply chain management.

\section{How to reference}

In order to correctly reference this scholarly work, feel free to copy and paste the following:

Mehmet Savsar (2006). Maintenance Management and Modeling in Modern Manufacturing Systems, Manufacturing the Future, Vedran Kordic, Aleksandar Lazinica and Munir Merdan (Ed.), ISBN: 3-86611-198-3, InTech, Available from:

http://www.intechopen.com/books/manufacturing_the_future/maintenance_management_and_modeling_in_m odern_manufacturing_systems

\section{INTECH}

open science | open minds

\section{InTech Europe}

University Campus STeP Ri

Slavka Krautzeka 83/A

51000 Rijeka, Croatia

Phone: +385 (51) 770447

Fax: +385 (51) 686166

www.intechopen.com

\section{InTech China}

Unit 405, Office Block, Hotel Equatorial Shanghai No.65, Yan An Road (West), Shanghai, 200040, China 中国上海市延安西路65号上海国际贵都大饭店办公楼 405 单元

Phone: +86-21-62489820

Fax: $+86-21-62489821$ 
(C) 2006 The Author(s). Licensee IntechOpen. This chapter is distributed under the terms of the Creative Commons Attribution-NonCommercial-ShareAlike-3.0 License, which permits use, distribution and reproduction for non-commercial purposes, provided the original is properly cited and derivative works building on this content are distributed under the same license. 